\title{
Estimation of acceptable levels of tumour promoters
}

\author{
E BOYLAND
}

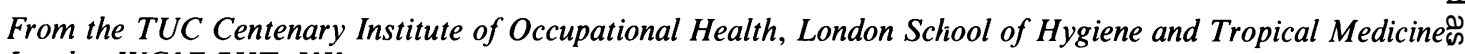
London WCIE 7HT, UK

The Ministry of Health set up a panel to consider "Carcinogenic risks in food additives and pesticides" in 1959. Their report included the following:

"Cocarcinogenesis. The panel decided that insufficient evidence was at present available for it to express any opinion about hazards to man from initiators or promoters."1

This statement was made in part because the work of Holsti ${ }^{2}$ and of Twort and Twort ${ }^{3}$ had shown that oleic acid-a normal food constituent - was a tumour promoter. Since 1960, knowledge of tumour promoters has increased but the risk to man of tumour promoters is still difficult to assess.

Tumour promoters are often weak complete carcinogens and those materials that are carcinogenic but not mutagenic are probably promoters. Although it is prudent to assume that there are no thresholds for tumour initiators, there must be acceptable levels for some tumour promoters. Of the types of promoter listed in the table, some evaluation of risk could be advanced for those products that can yield the high osmotic pressure probably needed for their promoting activity to be exerted. Sodium chloride, sodium saccharin, and sodium ascorbate are examples of compounds of this type. These three substances cause effects in cells such as sister chromatid exchanges, which are generally produced by tumour promoters. These effects, which may be taken as indicators of promoting activity, are dependent on concentration. Although high concentrations of sodium saccharin produce chromosome changes, concentrations of $1 \mathrm{~g} / \mathrm{l}$ or below do not and may be assumed to be "safe levels." Sodium saccharin could act by virtue of its surface activity in addition to its osmotic pressure.

If a person weighing $60 \mathrm{~kg}$ takes $30 \mathrm{~g}$ of sodium saccharin this would give a concentration of about $1 \mathrm{~g} / \mathrm{l}$ in the 301 of body fluid. If sodium saccharin were distributed in this way then by application of the usual "safety factor" of 100 an acceptable dose would be $300 \mathrm{mg}$ or 24 saccharin tablets of $12.5 \mathrm{mg}$.

Accepted 29 September 1986

These substances, however, are active because the恼 are concentrated in local areas. Sodium chloride is $\mathbf{2}$ promoter for the stomach where it is present in higl: concentrations. Sodium saccharin, sodium ascorbate and sodium nitrilotriacetate are concentrated in urine and promote cancer in the bladder and kidneys McChesney and Goldberg measured the concen tration of sodium saccharin in volunteers who toolo $1.17 \mathrm{~g}$ of the material. ${ }^{4}$ The concentrations in urine collected in the first eight hours after ingestion were $0 \cdot 785,0 \cdot 896$, and $1 \cdot 17 \mathrm{~g} / \mathrm{l}$ or about $1 \mathrm{~g} / \mathrm{l}$-a safe level If the usual safety factor of 100 is applied to this then one tablet $(12.5 \mathrm{mg})$ would be an acceptable dose ove eight hours. There are, however, many substances ${ }^{v}$ such as sodium chloride and water to which thif safety factor cannot be applied. In my opinion there is no convincing evidence that saccharin is a human car cinogen.

The concentration of sodium saccharin in the urine of rats fed diets containing $5 \%$ sodium saccharin is 0.2 molar which is about $40 \mathrm{~g} / \mathrm{l}^{5}$ This is 40 times the concentration which does not cause chromosome changes and also reduces the interfacial tensior between octanol and water by $20 \%{ }^{6}$

The 100-fold safety factor was proposed to allowe tenfold for possible differences between test animals and man and tenfold to allow for differences in

Tumour promoters

\begin{tabular}{ll}
\hline Type & Promoter \\
\hline Physical injuries & Wounds, $\mathrm{CO}_{2}$ snow \\
Foreign bodies & Bladder implants, asbestos \\
Infective agents & Hepatitis virus, bilharzia \\
Chemical irritants & Phorbol esters, iodoacetic acid, SOQ \\
Surface active substances & Bile acids, alcohol, sodium oleate, \\
& Tweens, saccharin, cyclamate \\
Preparations with high & Sodium chloride, iron dextran, \\
osmotic pressure & polymers \\
Metal salts & Lead, nickel, possibly cadmium \\
Chelating agents & Catechol, pyrogallol, \\
& 8-hydroxyquinoline \\
Solvents & Dodecane, benzene \\
Antibiotics & Griseofulvin \\
Antidepressants & Valium, phenobarbitone \\
Hormones & Stilboestrol \\
Antithyroid compounds & Thiouracil \\
Chloro compounds & DDT, tetrachlorodioxin, \\
& chloroform \\
\hline
\end{tabular}


human sensitivity. As the calculation for saccharin uses human data in part rather than animal it seems appropriate that a tenfold safety factor could be applied. With substances that are active only in high concentrations it is the toxic concentrations attained for any short period rather than the total dose that produces damage. These considerations illustrate the difficulties in calculating acceptable concentrations but I hope that they provide a possible approach to the problem.

\section{References}

1 Dodds EC, Barnes JM, Bonser GM, et al. Carcinogenic risks in food additives and pesticides. Monthly Bulletins of the Ministry of Health Public Health Laboratory Service 1960;19:108-12.

2 Holsti P. Tumour promoting effects of some long chain fatty acids in experimental skin carcinogenesis in the mouse. Acta Pathol Microbiol Immunol Scand 1959;46:51-8.

3 Twort JM, Twort CC. Comparative activity of some carcinogenic hydrocarbons. Am J Cancer 1939;35:80-5.

4 McChesney EW, Goldberg L. The excretion and metabolism of saccharin in man. I. Methods of investigation and preliminary results. Food and Cosmetic Toxicology 1973;11:403-14.

5 Hasegawa R, Cohen SM. The effect of different salts of saccharin on the rat urinary bladder. Cancer Lett 1986;30:261-8.

6 Boyland E, Mohiuddin J. Surface activity of some tumour promoters. IRSC Medical Science 1981;9:753-4. 